\title{
How much are family members satisfied with the intensive care unit in south Korea?
}

\author{
J Yoon*, G Lim, J Min, G Park, JY Shin, SI Park, YJ Cho, YJ Lee \\ From ESICM LIVES 2015 \\ Berlin, Germany. 3-7 October 2015
}

\section{Introduction}

Meeting the needs of family members of patients in the intensive care unit (ICU) is an important aspect of patient- and family-centered care.

\section{Objectives}

Lack of qualitative research on the ICU experience in South Korea hastens quality improvement. We evaluated the family members ICU experience.

\section{Methods}

We developed a survey asking the family members about their ICU experience, which evaluated the 3 major outcomes: (1)understanding of general information on ICU, (2)understanding of medical status of ICU patient, and (3)satisfaction of information received. The mean score of three outcomes, which represent overall family satisfaction with the ICU care, was calculated for each variable. The study was conducted at the medical ICU from August, 2014 to February, 2015.

\section{Results}

One hundred three surveys were returned. The satisfaction of information received had highest score(79.8 \pm 20.6), followed by understanding of medical status of ICU patient(76.0 \pm 19.4$)$, and understanding of general information $(58.5 \pm 23.9)$. The score of overall family satisfaction was $71.0 \pm 16.7$. The family members who need financial support and want meetings with social workers and the patient age over 70 year-old were associated with lower overall family satisfaction. The use of renal replacement therapy decreased the understanding of medical status of the ICU patient. The APACHE score over 25 decreased the understanding of general information on ICU. Multi-variate analysis revealed the

Seoul National University Bundang Hospital, Seongnam-si, Korea, Republic of patients age was significantly associated with decreased overall family satisfaction.

\section{Conclusions}

The age of the patient was an only significant factor associated with decreased family satisfaction. Further researches using validated questionnaire are essential to improve the family members ICU experience.

Published: 1 October 2015

doi:10.1186/2197-425X-3-S1-A657

Cite this article as: Yoon et al.: How much are family members satisfied

with the intensive care unit in south Korea? Intensive Care Medicine Experimental 2015 3(Suppl 1):A657.

\section{SpringerOpen ${ }^{\circ}$}

( 2015 Yoon et al.; This is an Open Access article distributed under the terms of the Creative Commons Attribution License (http:// creativecommons.org/licenses/by/4.0), which permits unrestricted use, distribution, and reproduction in any medium, provided the original work is properly cited.
Submit your manuscript to a SpringerOpen ${ }^{\circ}$ journal and benefit from:

- Convenient online submission

- Rigorous peer review

- Immediate publication on acceptance

- Open access: articles freely available online

- High visibility within the field

Retaining the copyright to your article

Submit your next manuscript at $>$ springeropen.com 